\title{
TE LLAMARÉ FEA
}

Paula Battaglino / paulabattaglino@gmail.com Marcela Lavandera / marcelalavandera@gmail.com

Romina Pereyra / romipereyra@gmail.com

Yamile Tournie / yamiletournie18@gmail.com

Teoría de la Historia. Facultad de Artes. Universidad Nacional de La Plata. Argentina

Recibido: 19/3/2020 / Aceptado: 9/6/2020

\section{RESUMEN}

El presente trabajo tiene como objetivo analizar una serie de documentos que se integran bajo la temática mujeres barbudas, pertenecientes al Archivo de Redacción del diario Crónica. Compuesta por fotografías y por recortes periodísticos, esta selección en particular pretende dar cuenta de cómo se construye la otredad en el imaginario popular. En nuestro caso, nos referiremos al uso de imágenes de mujeres con hirsutismo que fueron catalogadas como fenómenos ante los ojos de la sociedad.

\section{PALABRAS CLAVE}

Mujeres; barba; archivo; género

\section{WILL CALL YOU UGLY}

\section{ABSTRACT}

The following work focuses on the analysis of a series of documents under the thematic hairy women from the Editorial Archive of Crónica newspaper. Composed of photographs and newspaper articles, this particular selection gives an account of how the image of others is constructed in the popular imaginary. In our particular case, we refer to the use of images of women with hirsutism that were categorised as freaks in the eyes of the society.

\section{KEYWORDS}

Women; beard; archive; gender 
Los ecos del tránsito de la gran ciudad de Buenos Aires nos conducen a la Biblioteca Nacional Mariano Moreno. Un edificio inmenso se presenta a nuestra vista, una rampa nos deja sin aliento. Ingresamos, nos identificamos y se nos habilita para acceder al Departamento de Archivo. Allí, como habíamos acordado, nos espera la figura del arconte, quien resguarda el archivo, en el que se encuentra la gran parte de los ejemplares de la colección de todas las publicaciones de la Editorial Sarmiento.

Hecho de fragmentos, el archivo nos muestra imágenes de una época, de una multiplicidad de sujetos y de escrituras anónimas; el camino hacia él testigo casi exclusivo de los textos impresos, supone una elección y significa un itinerario. Es la fuente milagrosa de un pasado que se hace presente en su existencia, cercana y difusa; se nos presenta como un misterio encerrado en una caja, nos despierta el interés a lo desconocido, el asombro de su contenido nos genera incertidumbre. Documentos fotográficos, recortes de prensa, dibujos y caricaturas, acumulados dentro de sobres de papel madera, se guardan sigilosamente en un rincón de la Biblioteca.

\section{LA MAGIA DEL ARCHIVO}

Los sobres seleccionados contienen material reunido a lo largo del tiempo, en este caso están titulados como «Mujeres barbudas, velludas y feas», y están conformados por recortes periodísticos y fotografías en blanco y negro. Atrapa nuestra atención «Mujeres barbudas» en la Caja N. ${ }^{\circ} 896$ (AR00101844) que contiene ocho documentos periodísticos (1948-1984). Algo se encontraba allí, nos estaba esperando.

El archivo está vivo, integrado por documentos o por imaginaciones del pasado que se activan en el presente o en distintos presentes. Entonces, no solo está hecho de documentos, sino también de voces, de tonos, de modulaciones, de cuerpos, de miradasy de silencios; un archivo que se abre, se da a ver y se multiplica de manera escandalosa como desvelamiento de aquello que no puede ser develado. Hay en las cajas y en los sobres un marco $y$, sin embargo, hay profundidad: la caja es un soporte en el que se disponen imágenes y textos, cuyo orden genera relaciones diversas, se abre y se transforma.

La caja sobre la mesa y encima de esta última los sobres temáticos. En el interior de una caja, las imágenes, los recortes periodísticos, las citas envían las señales al orden. Una mesa para todo: para escribir, para fotografiar, para jugar con los guantes de látex, para mirar, para leer, para ordenar, para desordenar. ¿Cómo llevar el mundo a cuestas dentro de unas cajas? Lo que importa allí, entonces, más que las imágenes mismas, son las relaciones secretas que se establecen a partir de ellas. Esta mesa es el espacio de la construcción y la reconstrucción de una constelación de información viviente, guardada en forma de caja donde se crean y se recrean pequeños mundos o microcosmos; relaciones siempre móviles, historias posibles de imaginar.

Desconcertante, nos espera y nos seguirá esperando, nos atrapa, bajo una intencionalidad perturbadora, en cierto modo expresa un no dicho, lo visionario y lo trágico. Nos vigila. Así nace la sensación profunda de rasgar el velo, de atravesar la opacidad del saber y de acceder a un largo viaje incierto hacia el encuentro con aquellos rostros de mujeres barbudas atrapadas en la caja. La magia del archivo es un medio vacío donde reinaban las certezas y donde las palabras de hoy se expresan en un discurso inacabable sobre las mujeres y su olvido.

En la sala de la biblioteca el silencio se interrumpe cada tanto por el sonido de las hojas de los libros, el archivo contiene historias que se cuentan para tomar el camino de los actores que construyen relatos en la búsqueda de la conquista del sentido. 


\section{LA CONSTRUCCIÓN DE GÉNERO: CÓMO SER MUJER}

La historiadora francesa Arlette Farge (1991) se refiere a los relatos construidos por y sobre mujeres al mencionar que «hay poco espacio para elaborar un relato que no las anule ni las disuelva, que las mantenga disponible hasta que un día, en otro lugar, se haga otra narración de su enigmática presencia» (p. 95). Al abrir estas cajas llenas de contenido, las mujeres barbudas dejaron de estar atrapadas para andar por nuevos caminos y para construir infinitos sentidos de libertad.

Desde un análisis feminista de los documentos visuales del archivo, y basándonos en las reflexiones aportadas por Griselda Pollock (2013), se hace necesario repensar los modos de articulación entre las imágenes, las fotografías y los recortes periodísticos, comprendidas como elementos propios de un archivo de redacción. Posicionarnos desde este aspecto implica ocuparnos no solo de estas mujeres, sino de los sistemas sociales de representación y de los esquemas ideológicos que sostienen el eje de dominación del hombre por sobre ellas. Son tipificadas, descritas y catalogadas por otros; se trata de construir una idea de imagen de lo que no se tiene que ser para el género femenino. Como señala la mencionada autora, las intervenciones feministas demandan el reconocimiento de las relaciones de poder entre géneros. Advertirlas nos permite evidenciar los mecanismos del poder masculino hegemónico, la construcción social de las diferencia sexual y el papel que desempeñan las representaciones culturales en esa construcción que, a su vez, implican una jerarquización de los papeles masculinos por sobre los femeninos.

Resulta importante detenernos en la noción de género comprendida como una categoría socialmente construida que, a diferencia de otras cuestiones determinadas por la mera biología, supone el accionar de una cultura que define y estereotipa distintas características intelectuales, afectivas y emocionales; y que configura diversas normas que delimitan lo que puede $y$ debe ser masculino o femenino, las cuales establecen una diferencia tajante entre sexos.

Nos proponemos, pues, indagar sobre algunos de los siguientes interrogantes: ¿cómo se representan en las imágenes las relaciones de poder a partir de las diferencias sexuales? ¿Qué se muestra y qué se oculta de estas?

La producción de estas imágenes construyen un sentido, lo que implica no considerar a estos contenidos visuales solo como objetos, sino como una práctica cultural que repite y que legitima la idea de una esencia femenina en un contexto y en un momento histórico determinado. Debemos analizar cómo operan estas prácticas de representación, sitios de producción de sentido y posiciones desde los cuales esos significados deben ser consumidos por un espectador.

Es necesario estudiar estas imágenes en el contexto del archivo de redacción $y$, a su vez, observarlas insertas en su contexto de circulación original. De esta manera, intentaremos dar cuenta de la construcción de imaginarios que en distintos momentos se generan en torno a estas imágenes, y que nos permite hacer nuevas lecturas de ellas desde el presente.

\section{BIGOTES PARA EL SEXO DÉBIL}

Al adentrarnos en los recortes elegidos, nos preguntamos qué viene antes a nuestro encuentro, si la imagen o el texto, ya que ambos se combinan en un mismo espacio e intención. Quizás sean lecturas simultáneas. La palabra en diálogo con la imagen es portadora de significaciones de la experiencia lectora, por lo tanto, conecta con todas las posibilidades de interpretación (personal, contextual, social, cultural y simbólica). Es decir, la palabra y el texto ofrecen estructura y anclaje al significado de la imagen como representación de una porción de la realidad que permite establecer un compromiso con el 
lector, aquí la palabra condensa el significado de la imagen como inicio de todas las narraciones posibles.

Con una tipografía que se distingue del resto de la página por su tamaño relevante, ubicado en el extremo superior, nuestra vista se dirige al título de una nota: «Siempre hubo mujeres con toda la barba» [Figura 1]. Este artículo forma parte de la revista Ahora, publicada en junio de 1984. «No es patrimonio masculino el uso de la barba», leemos en el copete, un resumen de la información a modo de anticipo.

Figura 1. Recorte periodístico, «Siempre hubo mujeres con toda la barba» (1984). BNMM Departamento de Archivos. Fondo Editorial Sarmiento. Archivo de redacción de Crónica. Sobre temático: AR00101844 Mujeres barbudas

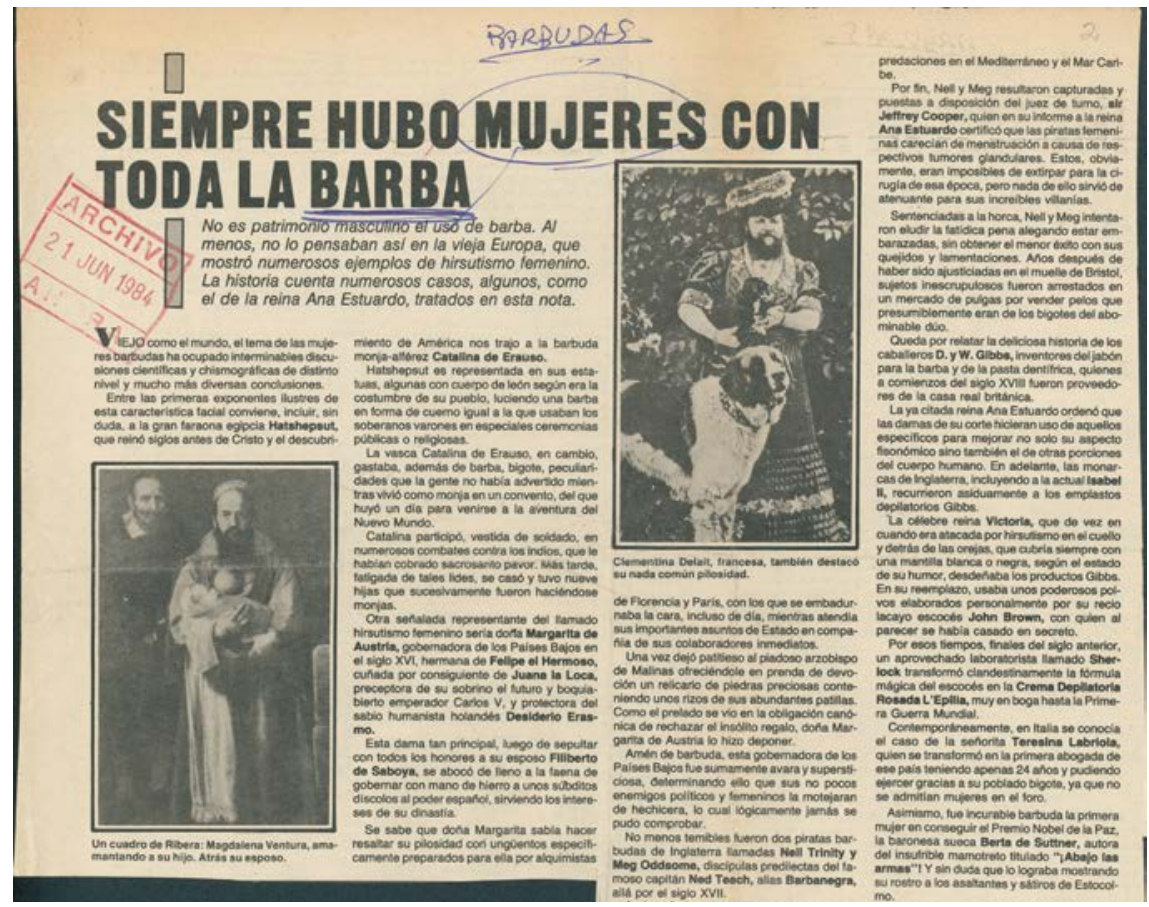

El contenido de la nota se refiere a distintos episodios de hirsutismo femenino que tuvieron lugar en la Europa entre los siglos XV y xIx; prácticamente todos los casos presentados pertenecieron a la realeza. Los pequeños relatos, que mencionan de forma acotada la biografía de ciertas mujeres que pasaron a la historia por su condición genética tan particular relacionan directamente su carácter o sus logros con esta característica. Como si la barba, uno de los más sustanciales ejemplos de virilidad, les diera ciertas virtudes que de otro modo estarían ausentes en su sexo débil.

En la mayoría de estos hechos, la barba fue considerada como un atributo a exhibir, digna de ser resaltada. Entendida como signo de poder o de posible fortaleza, les permitió a las mujeres que la portaban habitar determinados espacios y cumplir determinados papeles sociales entonces ocupados exclusivamente por hombres. Puede ser visto como una forma de perpetuación de una jerarquización del género, es decir, no creemos que sea una lectura positiva desde el posicionamiento de la historia o del relato textual al cual nos estamos enfrentando. Concebimos esta idea de falso poder en la asociación de la figura femenina por poseer un rasgo distintivo de la construcción visual de masculinidad.

Pollock, en el inicio de uno de los capítulos de su libro Visión y diferencia (2013), argumenta que en la historia oficial a las mujeres se las omite intencionalmente en pos de «una producción y perpetuación de la jerarquización del género» (p. 19). Nos preguntamos aquí si el énfasis puesto en los rasgos masculinos y en los papeles que ellas ejercieron en su vida se vincula directamente, ¿sus logros pasaron a la historia por un mero atributo físico discrepante?

Entendemos que esta aceptación del atributo barba está determinada por sistemas sociales y por esquemas ideológicos que sostienen la dominación de los hombres sobre las mujeres dentro de unos regímenes de poder en los que son igualmente influyentes la clase y la raza (Pollock, 2013). 
La diferencia sexual es producida mediante una serie interconectada de prácticas sociales y de instituciones que sostienen al sexo como criterio de poder que determinan el dominio masculino.

Las dos imágenes que acompañan al texto no tienen directa relación con lo que este describe, no representan ninguno de los casos mencionados, pero sí refuerzan visualmente las relaciones sociales de dominación del hombre, junto con la idea de exaltar su vellosidad abundante como algo fenoménico.

Por ejemplo, uno de los anclajes visuales es un cuadro de José de Ribera de 1631, donde se muestra a Magdalena Ventura amamantando a su hijo, el epígrafe debajo de la imagen es el que aporta los datos esenciales para reconocerlo. Una de las protagonistas del cuadro define su condición de mujer a través de la maternidad, a pesar de sus características físicas que responden a un modelo masculino; es mujer en tanto se muestra amamantando a su hijo. Tal vez, la decisión de pintar el cuadro de este modo es lo que viene a confirmar que la persona que observamos es mujer, de otra manera, sin los referentes contextuales exclusivos suficientes (como la ropa de mujer y el acto de la lactancia), el espectador no comprendería la rareza de lo representado.

La imagen mencionada sirve de apoyo y de anclaje del texto, por tal motivo puede considerarse a la imagen como un complemento de lo escrito, que sirve para facilitar su comprensión, donde ambos aportan parte del significado y de su interacción se enriquece el sentido del mensaje que se desea transmitir. En la misma página conviven otros temas con otros títulos variados y sin correlación alguna. Con el título «Difusión de la cultura árabe» se anticipa el contenido de otro artículo y, en el margen inferior derecho, se completa la página con una caricatura de humor.
Continuando con los archivos nos encontramos una fotografía [Figura 2] con un epígrafe que recita «Miss Anna Jones, la femme â barbe du cirquebarnum». Describe el caso de esta mujer barbuda «que llegó a ser la estrella de los fenómenos que exponía el famoso circo Barnum» a fines del siglo xIx. Trabajando allí prosperó económicamente, al mercantilizar su condición para subsistir dentro del mundo burgués capitalista; vendió su cuerpo como un espectáculo al cual observar.

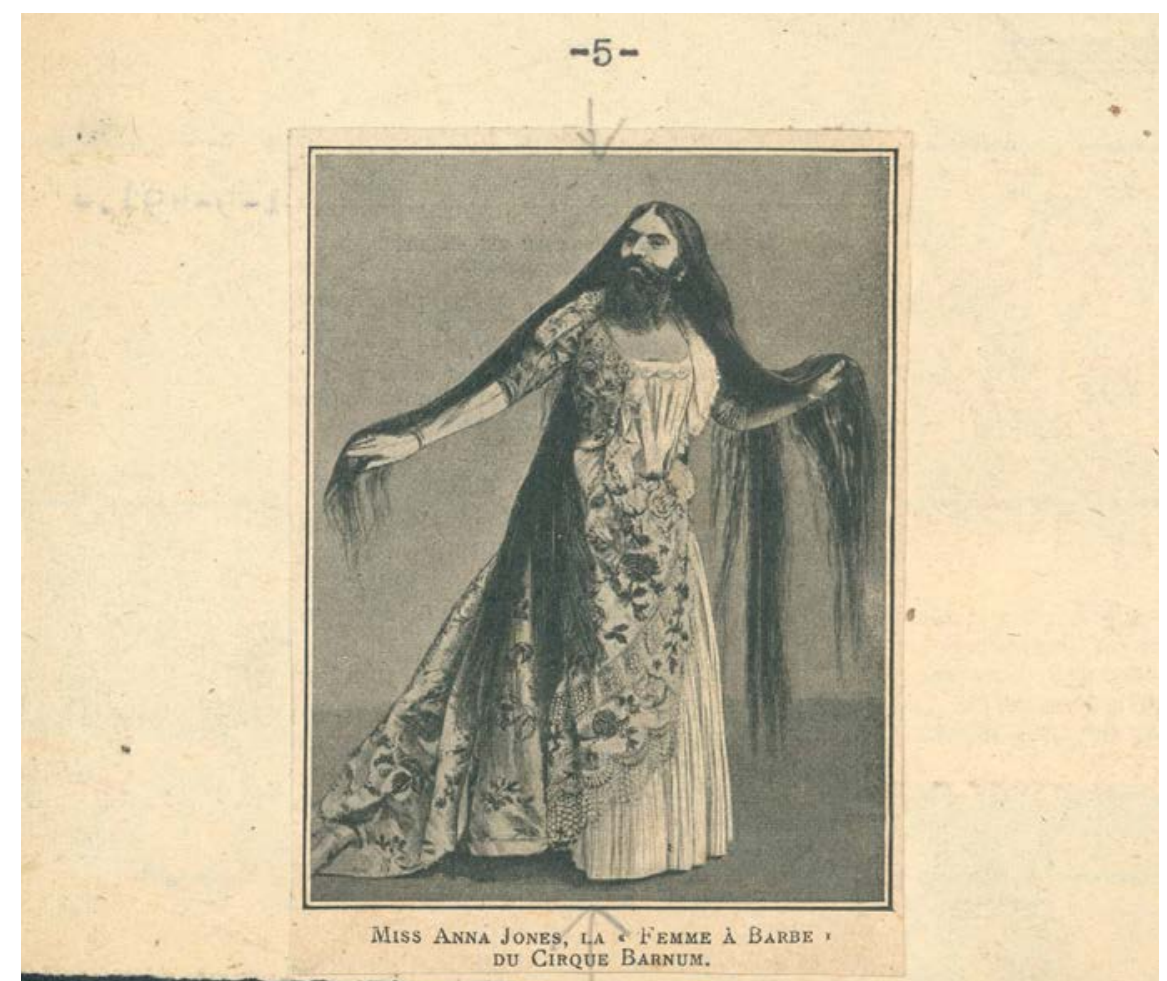

Figura 2. Recorte periodístico, Miss Anna Jones, La Femme â Barbe, du Cirque Barnum (1949). BNMM. Departamento de Archivos. Fondo Editorial Sarmiento. Archivo de redacción de Crónica. Sobre temático: AR00101844, Mujeres barbudas 
En su publicación original [Figura 3], la imagen se ubica en el extremo izquierdo de una columna y ocupa un pequeño recuadro en su interior $y$, a su vez, forma parte de una página de revista que lleva por título «Cosas de este mundo». La relación entre el contenido visual y el escrito es complementario, comparten y ocupan la misma cantidad de espacio se observa que otras notas con otros títulos se presentan en la misma página. Aparecen otras columnas, tales como «El ciclista más gordo del mundo» o «Velocidades de animales terrestres». Teniendo en cuenta estas consideraciones, podemos hablar de un tratamiento de los temas como una rareza, una curiosidad que escapa de esquemas tradicionales de la figura femenina y de los cuerpos.

Figura 3. Página completa de la revista Aquí Está, número 1378, página 27 (1949). BNMM Departamento de Archivos. Fondo Editorial Sarmiento. Archivo de redacción Crónica. Sobre temático: AR00101844 Mujeres barbudas

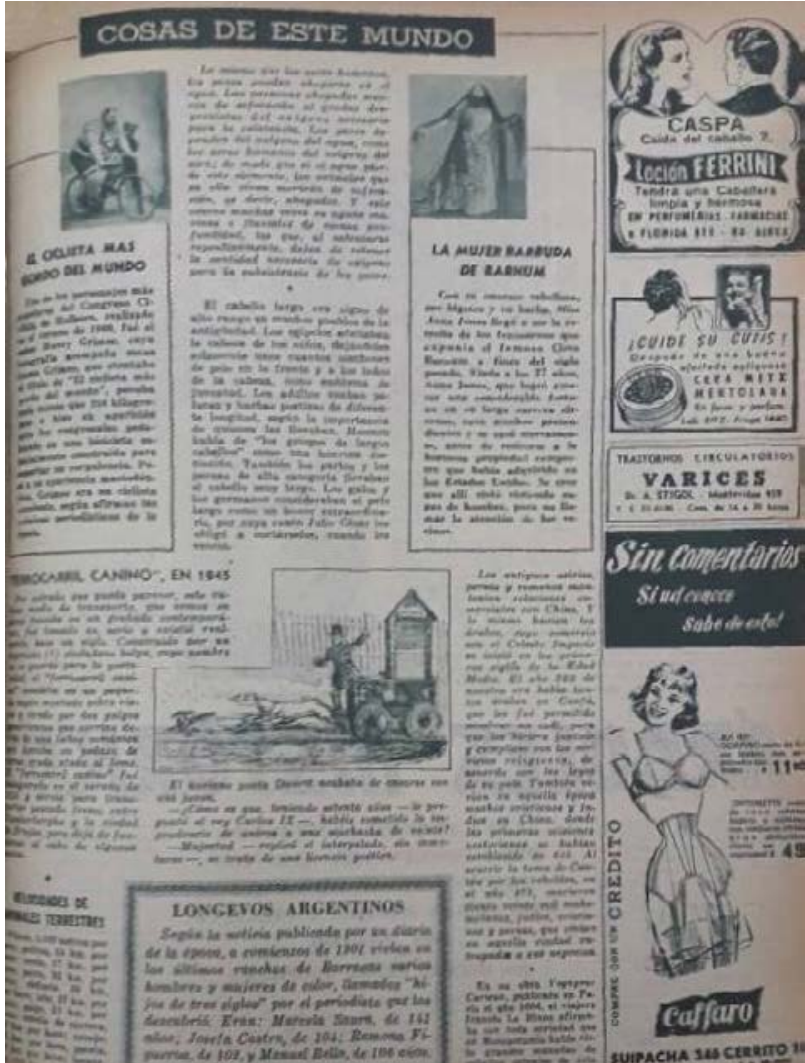

A lo largo de la página y en el extremo derecho de la misma se leen cuatro anuncios publicitarios que hacen mención a los cuidados del cuerpo y a la estética: caída de cabello, cuidado del cutis, corpiños y corsetería que modelan la figura. La lectura de esta publicidad, si bien parece casual en su ubicación, ya que se repite a lo largo de los márgenes de otras páginas, nos remite a esta problemática de la idealización de la belleza y de la mujer, en la cual las que poseen un rostro lleno de vello no encajan en el estereotipo normalizado.

Nuestro tercer elemento del archivo es una fotografía de Emmet y Priscilla Bejano, una pareja circense que resalta por sus peculiaridades [Figura 4] Nos devela las cualidades de las normas exhibidas en el circo, que elige como protagonistas a estos «seres monstruosos» desviados de los cánones estéticos corporales establecidos. La imagen se ubica al final de la hoja junto a otras fotografías en blanco y negro de personas que son la atracción del circo, la página se configura como un collage [Figura 5].

Figura 4. Fotografía de Emmet y Priscilla Bejano (s. f.). BNMM. Departamento de Archivos. Fondo Editorial Sarmiento. Archivo de redacción Crónica. Sobre temático: AR00101844, Mujeres barbudas

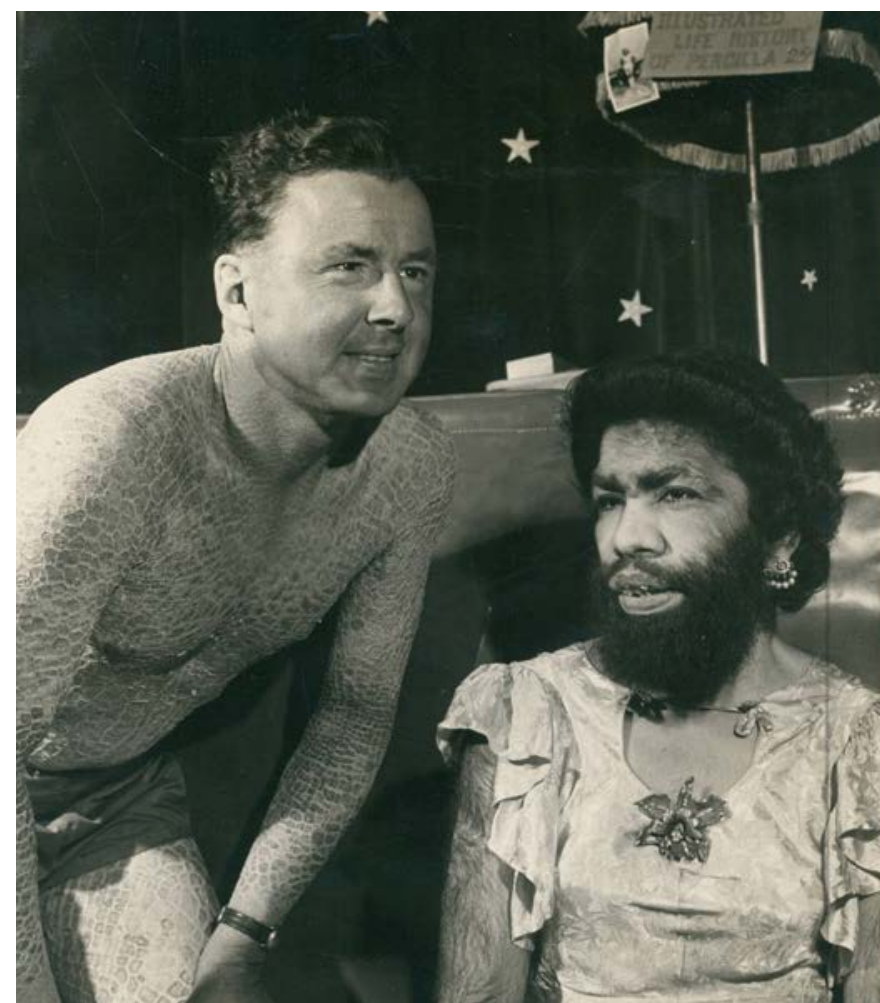




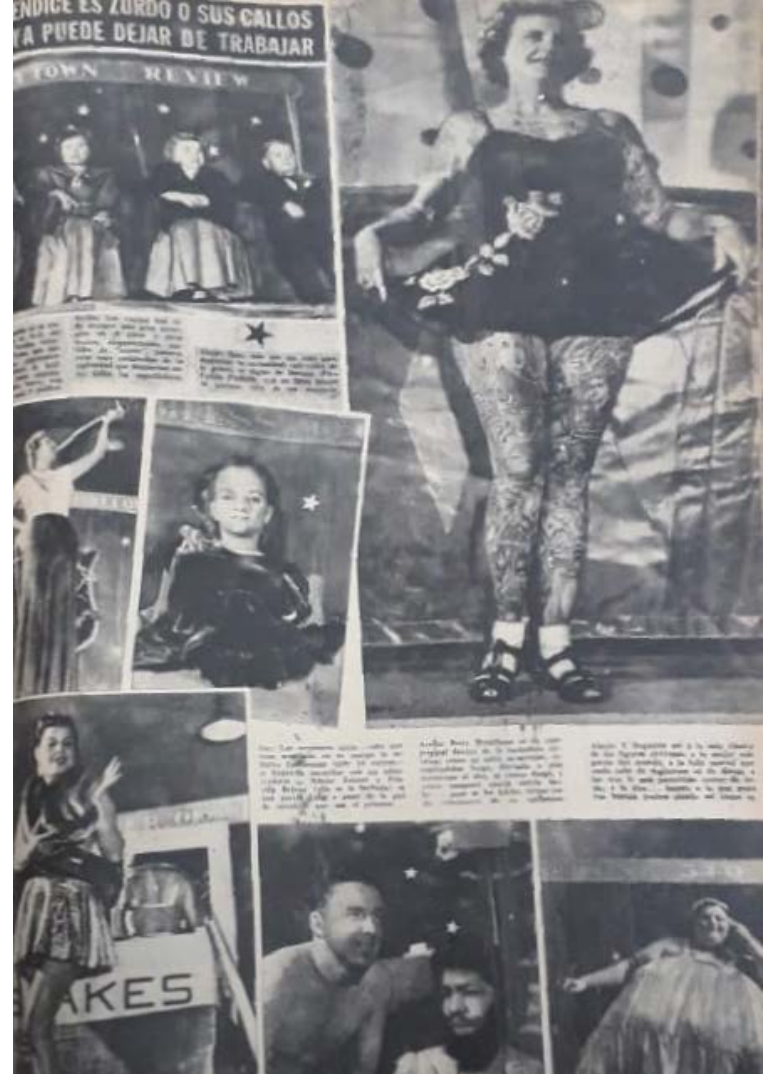

Figura 5. Página completa de la Revista Ahora, número 1845, página 15 (1951). BNMM. Departamento de Archivos. Fondo Editorial Sarmiento. Archivo de redacción de Crónica. Sobre temático: AR00101844 Mujeres barbudas

Los nomencladores aportados por el archivo responden al periodo histórico en que fueron creados, los tipos de clasificación, el vocabulario utilizado, las maneras de nombrarlos son parte de la historia de este archivo. Nos preguntamos aquí si esta forma de considerar a las mujeres, como objetos catalogables por su aspecto físico, ha cambiado o si se sigue perpetuando en medios de difusión y en el imaginario popular.

El archivo es la ley de lo que puede ser dicho, el sistema que rige la aparición de los enunciados como acontecimientos singulares (Foucault, 1979), como las Mujeres barbudas y sus historias de exclusión. Todas esas cosas dichas han tomado nuevas formas, han dejado de ser lo que unificaba el contenido de sus discursividades para transformarse en otras posibilidades enunciativas que el archivo dispone siendo siempre porvenir.

\section{REFERENCIAS}

Ahora. (1951). Ahora, (1845), 15 [Página completa de revista]. Archivo de redacción de Crónica (AR00101844 Mujeres barbudas). Biblioteca Nacional Mariano Moreno, Departamento de Archivos, Fondo Editorial Sarmiento, Ciudad Autónoma de Buenos Aires.

Allica, M. (21 de junio de 1984). Siempre hubo mujeres con toda la barba [Artículo periodístico]. Archivo de redacción de Crónica (AR00101844 Mujeres barbudas). Biblioteca Nacional Mariano Moreno, Departamento de Archivos, Fondo Editorial Sarmiento, Ciudad Autónoma de Buenos Aires.

Aquí está. (1949). Aquí está, (1378), 27 [Página completa de revista]. Archivo de redacción de Crónica (AR00101844 Mujeres barbudas). Biblioteca Nacional Mariano Moreno, Departamento de Archivos, Fondo Editorial Sarmiento, Ciudad Autónoma de Buenos Aires.

Farge, A. (1991). La atracción del Archivo. Valencia, España: Edicione Alfons el Magnánim.

Fotografía de Emmet y Priscilla Bejano. (s. f.). [Fotografía]. Archivo de redacción de Crónica (AR00101844 Mujeres barbudas). Biblioteca Nacional Mariano Moreno, Departamento de Archivos, Fondo Editorial Sarmiento, Ciudad Autónoma de Buenos Aires.

Foucault, M. (1979). La arqueología del saber. Ciudad de México, México: Siglo Veintiuno. 
Miss Anna Jones, La Femme â Barbe, du Cirque Barnum. (1949). [Recorte periodístico]. Archivo de redacción de Crónica (AR00101844 Mujeres barbudas). Biblioteca Nacional Mariano Moreno, Departamento de Archivos, Fondo Editorial Sarmiento, Ciudad Autónoma de Buenos Aires.

Pollock, G. (2013). Visión y diferencia. Feminismo, feminidad e historias del arte. Ciudad Autónoma de Buenos Aires, Argentina: Fiordo. 